\title{
The Investigation about the Influence of Establishing Xiongan New Area on College Students' Career Choice in Surrounding Area
}

\author{
Yanshu Niu ${ }^{1}$, Chuang Wang ${ }^{1}$, Jiayu Yong ${ }^{1}$, Xingya Wen ${ }^{1}$, Kefan $\mathrm{Ai}^{1}$ \\ ${ }^{1}$ North China Electric Power University, 2 Beinong Road, Huilongguan Town, Changping District, Beijing, \\ China
}

Keywords: Xiongan New Area; Beijing-Tianjin-Hebei urban agglomeration; student employment

\begin{abstract}
In April 2017, the Central Committee of the Communist Party of China, the State Council issued a notice, decided to set up Xiong' an New Area, which is a major decision made by the CPC central Committee with comrade Xi Jinping at the core to further promote the coordinated development of Beijing, Tianjin and Hebei. "Millennium plan" will drive the development of local industry and the surrounding economy, so as to increase employment opportunities, and ease the employment pressure of college students. As college students, it is essential to reflect the views of college students on Xiong' an New Area through the investigation of the post-graduation work of college students in Beijing - Tianjin - Hebei region. Research materials are finally sorted out and summarized to draw conclusions and write papers. It can be concluded that the surrounding college students generally care a little about the policy, and are willing to combine their own professional to do their best to consider working in Xiong' an. The research results will help college students understand the impact of university migration in Beijing, understand the employment situation in the context of Xiong' an New Area, and grasp the development opportunities. Through the investigation, college students have a more in-depth understanding of the principles and policies of the CPC.
\end{abstract}

\section{Introduction}

\subsection{Research Background}

On April 1, 2017, the CPC Central Committee and the State Council issued a notice and decided to establish the Xiong'an New Area in Hebei province [1]. To focus on relieving Beijing's non-capital functions, mitigating Beijing's metropolitan diseases, and capitalizing on the regional economic growth effects of capital cities, exploring new ways to optimize the development of population-intensive economic regions, stimulating the development of Hebei's economy, and adjusting and optimizing layout and spatial structure of Beijing and Tianjin. It is of great practical significance and far-reaching historical significance to balance the regional economy in the north and the south and foster innovation to drive the development of new engines.

The Xiongan New Area is located in Hebei Province, China, and is located in the hinterland of Beijing, Tianjin and Baoding. The planning area covers three small counties in the Xiong County, Rongcheng, and Anxin areas in Hebei Province and some surrounding areas. Xiongan New Area has obvious advantages in location and convenient transportation. The existing highways and railways can quickly form a half-hour commuting circle with Beijing, Tianjin and Shijiazhuang. The environment is beautiful, the ecological environment is excellent, and the carrying capacity of resources and environment is relatively high. Xiongan New Area which is low population density, low level of development and abundant development space, having high standards of development and construction.

Since the beginning of reform and opening up, the population of Beijing has rapidly increased and it has reached more than 21 million, close to the 23 million population control targets in 2020 . Beijing has already faced more serious urban disease problems: such as traffic congestion, high housing prices, and resource overload, etc. The reason for the hierarchy is to carry too many non-capital functions. If some non-capital functions are evacuated to Xiongan New Area and its 
surrounding areas not far from Beijing, it will not only ease Beijing's major urban diseases, but also stimulate the development of Hebei's economy and promote the integration process of Beijing-Tianjin-Hebei Urban Agglomeration [2].

\subsection{Research Purpose}

To understand the impact of college migration in Beijing. To observing the economic development in Hebei Province along with the development of Xiongan. To help college students understand the employment situation in Xiongan New District and grasp development opportunities.

\subsection{Research Significance}

Analyzing and reflecting the current hot spots of economic development can help college students, especially those in Hebei Province, understand the employment situation in Xiongan New Area and grasp the development opportunities. The results of this research are applicable: keeping up with the introduction of new policies, analyzing trends in the new employment situation, and providing college graduates in Hebei Province with information on employment development in the new situation. In addition, the exploration of the influence of the development of Xiongan New Area on the employment of college students in Hebei province is very little. The research on this aspect can lay the foundation for further study on the development of xiongan New Area [3].

\section{Research Content}

This research is divided into three parts: 1 . On - the - spot investigation, members went to xiong'an new area to experience the local customs. 2. Mass interviews, team members interviewed students in Beijing, Tianjin and Hebei region, to understand the views of local residents on the establishment of xiong'an new area and the impact of the establishment of the new district on them. 3. Questionnaire, through the issuance of the questionnaire to know their understanding of xiong'an new area policy. We classify the information on the questionnaire and then analyze it, and draw a conclusion.

\section{Research Process}

\subsection{Preliminary preparation}

In the early stage of research, the research team first do desk research. Refer to the documents related to the construction of the Xiongan New Area and employment in recent years, find literature on the development of the Pudong New Area and the Shenzhen Special Economic Zone, find literature on the employment situation of college students in recent years, and find documents and news on the construction of the Xiong an New Area. The research team members summarized their results. After discussion, they sought guidance from the instructor, considered the purpose and feasibility of the social research, and eventually formed the planning of the social research.

The purpose, significance, and overall feasibility and safety issues of this research activity are fully taken into account.

\subsection{Field trips}

The practice team conducted a total field trip and witnessed the current state of Xiongan New Area's construction. A preliminary understanding of the opinions of locals, especially local young people, on this decision, and a brief understanding of their ideological changes after the introduction of this decision. After that, the group interviewed the local residents of Xiong'an New Area and local college students to conduct in-depth research.

\subsection{Interview}

The interview was divided into two parts. The first part of the interview was for Hebei residents. Through interviews with residents of different age groups, occupations, and townships, we learned 
that the policy of building Xiong'an New Area has had an impact on the real life of local residents. We also learn the change of their thinking and their outlook for the future life. The second part is interviews with graduate students and people waiting for employment in the Beijing-Tianjin-Hebei region, to know whether their opinions on the future development of graduation are affected by the policy of Xiong'an New Area or not.

\subsection{Questionnaire}

Based on field trips and interviews with the masses, the research team obtained preliminary results and confirmed the research direction. Through research, Xiong'an New Area also gained a more objective and comprehensive understanding. The research team produced a questionnaire based on the investigation and interview results, including the understanding of Xiong'an New Area policies and the impact on the respondents' opinions about the choice of work. After the questionnaires were pre-investigated by small-scale groups, the research team revised and improved some problems. It was issued on a large scale among graduate students and students waiting for employment in Beijing, Tianjin and Hebei.

After the questionnaire was recovered, the research team summarized the research information, established a mathematical model, and used the mathematical analysis methods such as the analytic hierarchy process to analyze the results of the questionnaire and finally formed the results and reached a conclusion.

\section{Practical Results}

In the process of investigation, the research team apply questionnaire survey method, sampling survey method, random survey method and interview method and other method in order to obtain the following relevant data, in addition our team analyzed and summarized relevant data using mathematical analysis methods.

\subsection{The analysis and results of questionnaire}

The subjects of the survey were randomly selected. We distributed 300 questionnaires to undergraduates, graduate students and people waiting for employment in the Beijing-Tianjin-Hebei Urban Agglomeration. And 286 questionnaires were returned. The recovery rate of the questionnaires was $95.33 \%$. Excluding invalid questionnaires, among them 267 questionnaires were valid with an effective rate of 93.36\%, it meets the basic requirements for statistical surveys.

All the effective questionnaires in our collection, there are 137 males and 130 females, accounting for 51.31\% and 48.69\% respectively. Including 227 undergraduates, 38 graduates and 2 doctoral students which accounted for $85.02 \%, 14.23 \%$ and $0.75 \%$. The data is credible within the error of the theoretical value.

From the questionnaire, we can see that more than half of the 267 people surveyed are only poor understanding of the decision to build Xiong'an New Area(52.43\%),27.72\% of them don't know much, only $10.11 \%$ are very well aware, and even $9.74 \%$ of them have not heard of it.

Using this data, we can see that this decision has not yet been popularized in all areas of Beijing-Tianjin-Hebei Urban Agglomeration. 


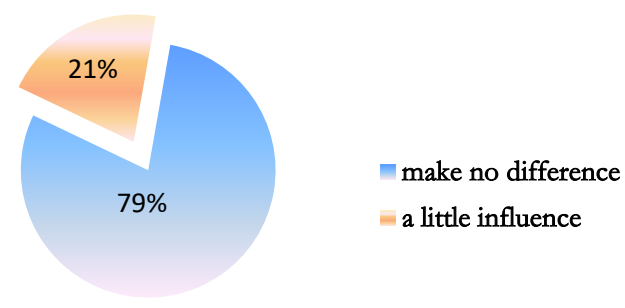

Fig 1. The influence of the establishment of Xiong an New Area on the life of the interviewee

Among the people who do not consider the employment in Xiong an new area, the most reason is that the workplace is far away from home, and some people think that the job prospects are not bright enough and the living environment is not ideal.

Table 1 why don't you choose to work in Xiongan new area?

\begin{tabular}{|l|c|c|}
\hline \multicolumn{1}{|c|}{ option } & total & \multicolumn{2}{c|}{ proportion } \\
\hline A.the direction of employment is not right & 4 & $9.76 \%$ \\
\hline B, the future of work is not clear & 37 & $19.58 \%$ \\
\hline C, the living environment is not ideal & 46 & $24.34 \%$ \\
\hline D, the place of work is far away from home & 92 & $48.68 \%$ \\
\hline $\begin{array}{l}\text { E, not taking into account the problem of } \\
\text { employment }\end{array}$ & 74 & $39.15 \%$ \\
\hline F, other & 32 & $16.93 \%$ \\
\hline
\end{tabular}

\subsection{Random interview}

The research group conducted random interviews with undergraduates and graduate students in Beijing, Tianjin and Hebei Province and the people with employment. The research group made some videos of the interview content, and formed a survey video through the editing, and the video is detailed in the appendix.

During the process of arranging interview materials, the research group showed some interviews as follows:

Table 2 The expectations for the development of Xiongan New Area

\begin{tabular}{|c|l|}
\hline NUMBER & What are your expectations for the development of Xiong an new area? \\
\hline 1 & $\begin{array}{l}\text { As a new coastal area, we can make certain contributions to the } \\
\text { development of inland areas. }\end{array}$ \\
\hline 2 & $\begin{array}{l}\text { We should share the pressure of Beijing's population and employment, and } \\
\text { develop towards a resource-saving and environment-friendly development. }\end{array}$ \\
\hline 3 & Don't be the next Beijing, the house price is not too high \\
\hline
\end{tabular}

After taking a variety of research methods, we have concluded that in the early stage of the decision of the Xiong an New Area, it will affect about 30\% of the graduate students in Beijing, Tianjin and Hebei Province, as well as the employment outlook, especially to the people in Hebei.

This decision has just come out soon. A large part of the students who are about to face employment are still in the state of watching. It is believed that after three years, five years, or even ten years and twenty years, when the new face has been developed rapidly, more and more young people in Beijing, Tianjin, Hebei and even all over the country will have a more profound impact. 


\section{Research Conclusion}

\subsection{Providing high quality educational resources for Hebei area}

Before the introduction of the policy, due to the relatively low investment in local education, many high schools in county towns had poor education. In terms of higher education, there was only one "211" university in Hebei. The establishment of Xiongan New Area will inevitably bring good news to Hebei's educational resources [4]. Many universities and colleges have moved to Hebei Province, benefiting college students in Hebei Province to benefit from more and better high-quality educational resources, so as to realize the positive feedback between local governments and universities.

\subsection{Employment opportunities for specific professional students}

In the situation where the employment situation of university students is not optimistic, Xiongan New Area has become the first choice for college students in the future. In the next 10 years, graduates in infrastructure, civil engineering, transportation, people's livelihood, health care, public service, logistics, business, and high-end R\&D will be very suitable for Xiongan New Area.

\subsection{Opportunities provided by enterprises for college students}

Xiongan New Area was set up for only four months, and there were companies that one more time held a job fair for university graduates. This aspect shown the attraction of Xiongan to a large number of companies and highlights the confidence of college students in the development of Xiongan New Area. Xiongan New Area is in a period of rapid development. At this time, some more dynamic groups are required to join in, and enterprises also provide opportunities for university students. Promote each other and let Xiongan develop better.

\subsection{Affecting the Employment of Students in Hebei Province}

About $20.69 \%$ of the survey respondents believe that this decision has already had an impact on their lives. Most impacts are on the direction of employment of people, among whom the majority are Hebei. It can be seen that the establishment of the Xiongan New Area has provided many employment opportunities for students in Hebei, allowing them to work in areas closer to home while enjoying the environments and economic of the new area.

\section{References}

[1] Information on http://www.gov.cn/

[2] Juan Gao. Research on the development thought of xiongan New Area under the background of coordinated development of beijing-tianjin-hebei region. [J]. Review of Economy and Management, 2017,33(06):130-136. (In Chinese)

[3] Hongrui Yang, Baiheng Liu, Tianchen Zhang. The Research on Talent Cultivation and Employment in Hebei Province under the Dual Background of Beijing-Tianjin-Hebei Collaborative Development and the Construction of Xiongan New Area. [J]. Journal of Hebei GEO University, 2017,40(06):130-134. (In Chinese)

[4] Cai Xiaolu. Humanistic Concern and Academic Commitment: Construction of Village History of Xiongan New Area[A]. Proceedings of The 23rd Association of Chinese Professors of Social Sciences in the United States (ACPSS) International Conference[C].2017:1. 